\title{
O PAPEL DO PROFESSOR DOS ANOS INICIAIS NA PRODUÇÃO DOS DISCURSOS DAS CRIANÇAS EM ATIVIDADES DE MODELAGEM MA̧TEMÁTICA ${ }^{1}$
}

\author{
Elizabeth Gomes Souza \\ Professora, Universidade Federal do Pará \\ Grupo de Estudos em Modelagem Matemática \\ elizabethmathematics@gmail.com \\ Ana Virginia de Almeida Luna \\ Professora, Universidade Estadual de Feira de Santana- Bahia \\ Coordenação Pedagógica, Escola Despertar- Núcleo de Estudo e Pesquisa em Educação \\ Matemática \\ andrluna@uol.com.br \\ Larissa Borges de Souza Lima \\ Professora, Escola Despertar- Núcleo de Estudo e Pesquisa em Educação Matemática- Bahia \\ 1.souzabb@hotmail.com

\begin{abstract}
Resumo
Este artigo tem por objetivo analisar como o professor exerce seu papel de orientador dos discursos a serem produzidos pelas crianças em uma atividade de modelagem matemática nos anos iniciais. Adotamos como aporte teórico, a perspectiva de aprendizagem como forma de participação, apresentado por Anna Sfard, bem como, alguns de seus conceitos teóricos. A trajetória metodológica adotada trata-se de uma abordagem qualitativa, por meio da observação, cujos resultados apontam três papéis que podem ser assumidos pelo professor na condução da produção discursiva dos alunos, ainda que seu discurso seja o discurso líder nessas atividades.
\end{abstract}

Palavras-chave: Modelagem, Anos iniciais, Aprendizagem, Participação, Discurso.

\section{THE ROLE OF THE TEACHER OF THE EARLY YEARS IN THE PRODUCTION OF CHILDREN'S DISCOURSES IN MATHEMATICAL MODELING ACTIVITIES}

\begin{abstract}
This article aims to analyze how the teacher plays his/her role as a supervisor of the discourses to be developed by the children in a mathematical modeling activity in their Early Years. To do so, we have based our research on the theoretical framework entitled: the perspective of learning as a way of participation, presented by Anna Sfard, as well as some of her theoretical concepts. The adopted methodology involved a qualitative approach, through observation. As a result, we have pointed out that three roles can be played by the teacher in conducting the students' discursive production although his/her discourse is the leading kind in those activities.
\end{abstract}

Key words: Modeling; Early Years; Learning; Participation; Discourse.

\section{Introdução}

\footnotetext{
${ }^{1}$ Boletim Gepem (Online) ISSN: 2176-2988 | n. 64 - Jan./Jun. 2014 (texto em diagramação).
} 
No presente artigo buscamos analisar como o professor exerce seu papel de orientador dos discursos a serem produzidos pelas crianças em uma atividade de modelagem matemática ${ }^{2}$ nos anos iniciais. Esta pesquisa fundamenta-se teoricamente no enfoque participacionista, inspirado nos estudos de Sfard (2008).

A aprendizagem como participação no discurso é a principal noção teórica de Sfard (2008), que retrata o desenvolvimento individual como resultante em primeiro plano, da participação do indivíduo em atividades coletiva e, historicamente, elaboradas pelos seres humanos. Com isso, o ser humano, ao nascer, encontra-se imerso em atividades sociais já elaboradas, tais como: formas específicas de falar, andar, resolver problemas matemáticos, dentre outros (SOUZA; BARBOSA, 2009).

Assim, de acordo com Sfard (2008), os indivíduos imersos nessas atividades inicialmente as reproduzem para, posteriormente, elaborarem formas individuais de fazer essas atividades coletivas. Neste estudo investigamos a aprendizagem como participação no ambiente de modelagem, já que entendemos a modelagem como um ambiente de aprendizagem no qual os alunos são convidados a investigar e a indagar (BARBOSA, 2003), por meio de conceitos matemáticos, situações-problema advindas do campo de trabalho, de outras ciências, do dia a dia, etc. (BARBOSA, 2003).

As seções deste artigo estão organizadas do seguinte modo: na seção a seguir, Modelagem Matemática nos anos iniciais, discorremos sobre a Modelagem como ambiente de aprendizagem nos anos iniciais do Ensino Fundamental; na seção 2 intitulada, Aprendizagem como participação no discurso, apresentamos o quadro teórico do estudo, com base em Sfard (2008). A seção 3 é dedicada à exposição dos métodos e à apresentação do contexto da pesquisa. As seções 4 e 5 são de apresentação e discussão dos dados. Por fim, na última seção apresentamos as considerações finais desta pesquisa.

\section{Modelagem matemática nos anos iniciais}

De acordo com o entendimento de Orey e Rosa (2007), a educação direcionada para a eficiência sociocrítica busca adotar práticas diferenciadas, pois os alunos devem ser vistos como agentes participantes na dinâmica do processo de ensino e

\footnotetext{
${ }^{2}$ Para evitarmos repetições, por vezes, utilizaremos o termo modelagem para nos referir à modelagem matemática.
} 
aprendizagem. Nessa direção, as salas de aula de matemática devem ser vistas como ambientes de desenvolvimento da capacidade criativa necessárias para 0 desenvolvimento do pensamento crítico e para a resolução de situações-problema pelos alunos.

A perspectiva sociocrítica, tal como discutida em Barbosa (2003), dirige este debate para a prática de modelagem em sala de aula, entendendo esta como uma oportunidade para se reconhecer o poder formatador da matemática ${ }^{3}$ e desafiar a ideologia da certeza. $\mathrm{O}$ autor ressalta que a adoção dessa perspectiva não implica na subtração de outros propósitos, como o desenvolvimento da teoria matemática e das habilidades de resolução de problemas aplicados.

Neste sentido, além de informar matematicamente, é preciso educar criticamente por meio da matemática (BARBOSA, 2003). Esse tem sido um ponto importante assinalado, no ambiente de aprendizagem da modelagem matemática, pela perspectiva sociocrítica, possibilitando que os alunos percebam os possíveis vieses dos modelos matemáticos nas investigações de questões da realidade.

No âmbito da inserção dos estudos da modelagem nos anos iniciais do Ensino Fundamental, foram localizadas poucas publicações. Em um estudo anterior Luna, Souza e Santiago (2009), enfatizam o quanto a modelagem pode suscitar o desenvolvimento da criticidade das crianças sobre assuntos sociais.

Nessa mesma direção, Caldeira (2007) desenvolveu uma atividade de modelagem com alunos pertencentes aos anos iniciais. As crianças de $4^{\circ}$ e $5^{\circ}$ anos escolheram como temática da atividade, a construção de uma horta. O pesquisador apontou outros aspectos relevantes nas atividades de modelagem, como o reconhecimento e a inclusão dos saberes e da linguagem matemática específicos do contexto cultural das crianças, na dinâmica dessas atividades.

Semelhante aos estudos anteriores, Lamon (2003), ao desenvolver atividades de Modelagem com crianças dos anos iniciais, destacou que elas tornam-se hábeis em construir modelos matemáticos representativos de problemas reais.

É importante destacar também que, o uso da modelagem nos anos iniciais do ensino fundamental pode desenvolver aspectos como interação, motivação, contextualização, problematização; interdisciplinaridade e diálogo investigativo, que

\footnotetext{
${ }^{3}$ Entende-se poder formatador da matemática pela ideia de que os argumentos sociais pautados em matemática são indiscutíveis e não são passíveis de crítica porque ideologicamente a matemática é uma ciência da certeza, da precisão e da objetividade (SKOSMOSE, 2001).
} 
podem contribuir com a aprendizagem da matemática pelas crianças desde a fase inicial da sua escolaridade (SILVA; KLÜBER, 2011).

\section{Aprendizagem como participação no discurso}

Neste artigo, buscamos compreender o papel do professor na elaboração da produção matemática dos alunos, com base em alguns conceitos teóricos apresentados por Anna Sfard. Em seu livro, Sfard (2008) delimita a matemática produzida e abordada no contexto escolar, de discurso matemático escolar. O termo teórico discurso tem uma caracterização ampla e corresponde à produção oral, escrita, gestual e outras diversas maneiras de comunicar utilizada e produzida no contexto escolar, nas aulas de matemática.

O uso desse termo como ferramenta teórica advém do seguinte entendimento que o fundamenta: os seres humanos não são produtos de um desenvolvimento individual que ocorre em um nível interno ${ }^{4}$. A aprendizagem humana, em qualquer âmbito, se desenvolve pela e na participação ${ }^{5}$ humana em diversas atividades socialmente elaboradas. É a partir dessa participação que o individuo elabora maneiras particulares de realizar o que aprendeu na participação dele nessas atividades, o que autora denomina de individualização (SFARD, 2008).

Para Sfard (2008), o processo individualização só é possível por meio de produções discursivas, sejam orais, escritas, gestuais, simbólicas, entre outras. É a comunicação que viabiliza a existência de atividades coletivas e a aprendizagem individual das mesmas.

Assim, Sfard (2008) adota, como objeto de análise, três específicos eixos: o discurso (a produção discursiva propriamente), os discursantes (as pessoas que participam do discurso) e a comunidade discursiva (o grupo de pessoas que participam desse discurso, em termos de coletividade). Participar em um discurso significa comunicar-se segundo regras instituídas pela comunidade discursiva.

Sfard (2008) esclarece que para aprender um discurso faz-se necessário a ajuda de um discursante já participante. Para Sfard (2008), o discursante já participante ou

\footnotetext{
4 A perspectiva participacionista de aprendizagem, enfatiza que a aprendizagem não é produto da realização de esquemas mentais particulares, e sim, da participação via comunicação das pessoas na vida coletiva (SFARD, 2008).

${ }^{5}$ O termo participação utilizado por Sfard (2008) tem inspiração em Wenger (1998).
} 
experiente (o professor) tem um papel imprescindível na aprendizagem de discursantes iniciantes, os aprendizes.

Com isso, Sfard (2008, p. 283) concebe a aprendizagem do discurso matemático escolar, como sendo um processo de "alinhamento" pelo aprendiz à produção discursiva de um participante experiente.

Dessa maneira, Sfard (2008) classifica a produção discursiva do professor, como sendo o discurso líder. Em outras palavras, a produção discursiva dos aprendizes deve seguir a produção discursiva do discursante experiente.

Todavia, os estudos de Sfard (2008) sugerem que a autora entende que esse alinhamento por parte dos alunos à liderança do discurso do professor se institucionaliza de maneira tácita. Por conta disso, a autora esclarece que acordos entre os participantes iniciantes e os participantes experientes são condições necessárias à aprendizagem de um discurso.

Sfard (2008) relata a existência de pelo menos três acordos entre os discursantes que são essenciais à aprendizagem. Eles se referem ao acordo sobre o discurso líder, sobre o papel dos discursantes e acordo sobre o curso da mudança discursiva.

De acordo com Sfard (2008), é necessário que os aprendizes adotem o discurso do professor, como discurso líder. Esse se configura como primeiro acordo. Contudo, a autora destaca que embora essa liderança seja tradicionalmente predeterminada e não negociável, ela precisa ser objeto de escolha pelos aprendizes.

O segundo acordo descrito por Sfard (2008) como condição para a aprendizagem de um discurso, refere-se ao acordo sobre o papel dos discursantes. Enquanto o professor deve assumir o papel de apresentar o discurso matemático escolar aos aprendizes e se sentirem responsáveis pelo alinhamento na produção discursiva dos aprendizes, os alunos "devem se mostrar confiantes na liderança do professor e seguirem os passos por ele indicados" (SFARD, 2008, p. 284, tradução nossa).

O terceiro acordo, diz respeito ao acordo que os discursantes devem ter em relação ao curso da mudança discursiva dos aprendizes. Para Sfard (2008), ambos os discursantes, o professor e os alunos devem ter clareza a respeito do objetivo da aprendizagem, a saber: a produção pelos aprendizes do discurso matemático escolar.

Na seção seguinte, descrevemos o método utilizado no estudo, para a obtenção, análise dos dados, bem como, apresentamos o contexto da pesquisa. 


\section{O método e o contexto}

Este estudo tem como propósito compreender o papel do professor em atividades de modelagem na produção de discursos pelos alunos. Tal objetivo caracteriza a pesquisa como uma pesquisa qualitativa (DENZIN; LINCOLN, 2005). Tendo em vista que objetivamos identificar o papel do professor na produção discursiva dos alunos, escolhemos como objeto de tal análise, a própria produção discursiva dos sujeitos.

Obtivemos a produção discursiva dos alunos e da professora, adotando como procedimento de coleta de dados, a observação (ANGROSINO, 2005), por meio de gravações em áudio, que em seguida foram transcritas e analisadas.

Buscamos compreensões sobre o papel do professor em atividades de modelagem na produção discursiva dos alunos, a partir da produção discursiva de uma professora e de 22 (vinte e duas) crianças $^{6}$ do $4^{\circ}$ ano do Ensino Fundamental, que vivenciaram uma atividade de modelagem, cujas falas estão numeradas para diferenciálas.

Inspiramo-nos em Chamaz (2006) para realizarmos a análise dos discursos das crianças. Por conta disso, realizamos uma análise inicial descritiva dos dados e em seguida contrapomos essa análise com os conceitos teóricos citados ao longo do artigo. A seguir, apresentamos a primeira análise citada.

\section{A atividade de modelagem e os discursos produzidos: uma análise descritiva}

A professora da turma escolheu desenvolver uma atividade de modelagem abordando o tema Água virtual. Em sala de aula, a professora apresentou às crianças um vídeo, juntamente com um texto explicativo sobre a temática.

Nessa seção, apresentaremos uma análise descritiva da produção discursiva das crianças e da professora, sem inicialmente, adotarmos, refutarmos ou ampliarmos, os termos teóricos apresentados. A seguir, apresentamos a produção discursiva das crianças e da professora no momento posterior à apresentação de dois vídeos sobre a água virtual.

\footnotetext{
${ }^{6}$ Para preservar a identidade das crianças nos fragmentos de apresentação dos dados foi utilizada a abreviação Cça.
} 
[18]Prof ${ }^{a}$ : Depois do vídeo que assistimos, o que vocês imaginam agora ser água virtual?

[19]Cça 2: Toda água que a gente consome.

[20]Prof ${ }^{a}$ : Toda que a gente consome onde? $O$ que é água virtual?

[21]Cça4: É a água que a gente bebe, usa da torneira, que pode usar para lavar carro.

[22]Profa: : É só essa água?

[23]Ç̧a 6: Para fazer a placa do carro, muitas outras coisas, fazer alimento...

[24]Profa : Serve para fazer o cimento das nossas casas ou da indústria?

[25]Cça 5: Na indústria.

[26 Profa: Como?

[27]Cça 1: Usa para fazer produtos: borracha, cimento, vidro, tudo feito na indústria.

Nesse segundo trecho selecionado para análise, observamos que as crianças já produzem discursos coerentes sobre água virtual, a partir das informações apresentadas no vídeo. As perguntas da professora aos alunos sobre como a água virtual é usada na indústria (26), sobre aonde essa água é usada (20), se água virtual se refere somente a água que se usa na torneira para lavar o carro, etc. (22), são exemplos que objetivam ampliar a produção discursiva das crianças sobre o conceito de água virtual.

Em seguida, apresentamos a produção discursiva realizada pelas crianças em interação com a professora, após a leitura de um texto impresso sobre água virtual.

[63]Prof : Na leitura que a gente acabou de ler, diz que o Brasil exporta soja para outro país e que durante o ano gasta 45.000.000 de metros cúbicos de água.

[64]Ç̧a 2: Oh pró, o que é cúbico?

[65]Prof ${ }^{\text {a }}$ É a medida, por exemplo, da profundidade de uma piscina.

[66]Cça 6: Na internet aqui, a pró viu que uma piscina - aquelas piscinas atléticas que Gustavo Borges nada, disse que tem $2.700 \mathrm{~m}^{3}$ de água.

[67]Prof : Vamos fazer esse cálculo? Eu queria saber quantos 2.700 cabem em 45.000.000.

[68]Cça 6: É de vezes ou de divisão?

[69]Prof ${ }^{a}$ : Quantos 2.700 cabem em 45.000.000? Qual estratégia?

[70]\{Uma criança pega a calculadora e faz divisão. Deu 16.373\}.

[71]Prof ${ }^{a}$ : Isso mesmo. Gente, olha o que a gente descobriu... para que o Brasil produza soja em 1 ano, quantas piscinas de águam precisam para produzir?

[72]Cça 7: 16. 373.

[77]Prof : Isso é pouco ou muito?

[78] Cças: Muita.

Nas transcrições das falas apresentadas acima, notamos que a produção discursiva produzida sobre metro cúbico, foi produzida por uma criança (64), com base em informações presentes no texto dado pela professora. Quando questionada, a professora comparou o conceito matemático dessa medida à profundidade de uma piscina, a fim de tornar a ideia de metro cúbico vinculada a uma situação que fazia parte do repertório discursivo da criança (a profundidade de uma piscina). 
A partir dessa comparação, uma das crianças resolveu identificar a profundidade de uma piscina, tendo como referência uma piscina atlética. Essa informação foi tomada como fonte para a análise da quantidade de água que o Brasil utiliza para a produção de soja durante 1(um) ano. A análise de que essa quantidade corresponde a 16.373 piscinas, levou a professora a suscitar das crianças uma análise sobre esse quantitativo, "é muito ou pouco?" (77), obtendo como resposta pela criança que essa quantidade representa um quantitativo grande (78).

A partir da leitura do texto apresentado anteriormente, a professora solicitou às crianças que fizessem uma pesquisa. A referida pesquisa tinha o seguinte encaminhamento: Quais os impactos comerciais e hídricos que a utilização da água virtual tem nos produtos consumidos nas três refeições diárias ${ }^{7}$ ?

A seguir, iremos apresentar os encaminhamentos que foram realizados pelos alunos em grupo.

$1^{\circ}$ grupo

[1]Profa: São quantos aqui? 5? Quantos dias na semana vocês comem carne (de boi)?

[2]Cça 9: Todos os dias.

[3]Prof ${ }^{\text {a }}$ :São quantos dias na semana?

[4] Ç̧a: 7.

[5]Prof : \{com os dados deles nas mãos\} Cada um de vocês, cada família, comem $26 \mathrm{~kg}$ de carne em uma semana. Agora eu queria que vocês calculassem quantos litros de água virtual a família de vocês gasta por semana. $1 \mathrm{~kg}$ de carne $=13.000$ litros. Então vamos estimar, depois eu volto para ver.

$2^{\circ}$ grupo

[1]Ç̧a 8: a água é um direito humano por ser essencial à vida de todos. $70 \%$ de água são para produção de alimentos, $8 \%$ uso doméstico, $22 \%$ indústrias.

[2]Prof ${ }^{\text {a }:} \mathrm{O}$ que vocês podem aproveitar com os dados da pesquisa?

[3]Ç̧a 10: Fazer um cartaz.

[4]Prof ${ }^{\text {a }}$ : De que forma? Pode ser gráfico!

Embora diferentes, ambos encaminhamentos tiveram como objetivo a produção discursiva que envolvia números, ou representação numérica, como é o caso da sugestão para que as crianças elaborassem gráficos. A seguir, apresentamos a produção discursiva do grupo 3 e que informações a professora indicou que as crianças elaborassem.

$3^{\circ}$ grupo

[8]Prof : Diante de sua pesquisa o que você achou mais interessante?

[10]Ç̧a 5: Uma maçã consome 70 litros de água virtual. $1 \mathrm{~kg}$ de coco consome 2.500 litros. São utilizados numa xícara de café 140 litros de água. São necessários 21.000 litros para $1 \mathrm{~kg}$ de café, tornando o chá mais econômico, gastando apenas 30 litros de água.

[11]Prof ${ }^{a}:$ Então, você observa que é melhor fazer chá ou café?

\footnotetext{
${ }^{7}$ A professora solicitou que essas informações fossem referentes ao consumo individual de cada criança e que suas respostas fossem socializadas nos grupos.
} 
[12]Cça 5: Chá, porque gasta menos.

[13]Prof : Vamos ver a diferença que gasta de chá para o café?

[14]Cça 4: Agora vou mostrar por produtos. Produtos de origem animal: queijo, 5.000 litros; ovos, 3.300 litros; leite 1000 litros.

[15]Prof : Cça3, eu gostei muito desses dados que você trouxe. Produtos de origem animal e de cultura. Vocês poderiam fazer quanto os produtos gastam mais, se é o de cultura ou de origem animal.

[17]Ç̧a 3: Pró, a gente pode juntar todos de cultura e todos de animal, no final a gente pode ver qual é o número que tem mais, se é de cultura ou animal.

[18]Prof : Isso... interessante. Vocês têm duas apresentações legais que é ver qual a diferença entre o chá e o café, para se consumir. Cça3, você trouxe mais alguma coisa interessante?

Semelhante ao que observamos na análise anterior, a professora adota a produção discursiva da criança, referente às informações pesquisadas por elas, para apontar alguns direcionamentos e solicitar específicas produções discursivas, como por exemplo, em (13), a professora solicita que a criança faça a diferença do que se gasta em chá e em café.

No entanto, analisando as falas (17) e (18), podemos identificar que a professora aceita que a criança proponha um direcionamento para as suas próprias produções discursivas.

A seguir, apresentamos as falas referentes à interação discursiva entre a professora e o quarto grupo.

\section{$4^{\circ}$ grupo:}

[1]Prof": Grupinho, o que vocês trouxeram sobre água virtual?

[2]Cça 4: No café da manhã eu gasto 800 litros de água. No almoço 1000 litros de água e no jantar 900 litros de água. Água virtual é aquela utilizada na produção de alimentos, é aquela água que você não vê.

[3]Prof ${ }^{\text {: }}$ O que mais te chamou atenção ao fazer sua pesquisa?

[4]Cça 4: Que a gente acha que gasta pouca água, mas a gente gasta muito, que quando a gente pega a conta de água não vem o que a gente gastou para fazer os produtos.

[5]Prof ${ }^{\mathrm{a}}$ Isso mesmo!

[6]Ç̧a 4: Só vem a água que a gente gasta em casa.

[7]-Prof ${ }^{\text {a }}$ Você falou uma coisa interessante. Pega ali o arroz Cça4 (produtos que tinham na sala de aula para doação da páscoa), para vermos se no arroz tem dizendo a quantidade de água virtual gasta. Será que tem?

[8]Cça 4: Eu acho que não pró!

[9]Prof : Vamos ver... Você falou uma coisa interessante. Você disse que a conta de água não vem informando. Será que no alimento diz? Aqui diz o valor energético, carboidratos, fibras, vitaminas.

[10]Cça 11: Só tem informando o quilo.

[11]Prof ${ }^{a}$ Algum momento vem informando o gasto de água virtual?

[12]Cça 11: Não!

Nesse trecho podemos observar que a professora avalia a produção discursiva da criança e confirma como coerente a informação apresentada pela mesma (5) sobre água virtual. A criança afirma que se consume uma quantidade expressiva de água na 
produção de alimentos, porém essa produção não vem referenciada na fatura do consumo mensal de água.

A partir dessa constatação realizada pela criança, a professora promove outra produção discursiva a respeito da água virtual: a identificação de que nos próprios alimentos também não é indicado o consumo total de água virtual do mesmo, ver nas falas (7), (9) e (11).

Os discursos apresentados a seguir referem-se também à produção discursiva do quarto grupo:

[19]Cça 4: Oh pró! O queijo pra mim gasta muito, porque você rega o capim, a vaca come para botar o leite e depois fazer o queijo.

[20]Prof ${ }^{\mathrm{a}}$ : Interessante isso, pois estamos estudando em nosso Projeto Amazônia cadeia alimentar.

[21]Cça 2: Para se ter uma manteiga gasta 18.000 litros de água virtual que foi toda água para fazer a manteiga. Oh professora! Para gente ter a manteiga, primeiro pega o capim para alimenta a vaca.

[22]Prof : Olha! Você fez o ciclo interessante.

[23]Ç̧a 2: Deixa eu mostrar (um desenho que ela fez no caderno mostrando uma cadeia alimentar com o gasto de água virtual). Ainda tem o curral da vaca para limpar de água.

[24]Profa: Certo!

[25]Ç̧a 4: Professora, o capim vai para a vaca, que a gente obtém o leite, o leite a gente tem que fazer a manteiga, é muita água!

[26]Prof ${ }^{\mathrm{a}}$ : Sabe o que vocês poderiam apresentar para os colegas? O ciclo!

Nesse específico grupo, a pesquisa das crianças sobre água virtual envolveu um ciclo de produção de um determinado alimento, nesse caso, a produção de leite. Inicialmente, essa produção discursiva é aprovada pela professora que avalia como uma produção legítima (20).

Nesse caso, a professora não enfatizou a produção do discurso matemático, em particular, e sim, uma produção discursiva coerente no que se refere à compreensão do ciclo de gastos com água de um determinado produto, sugerindo que esse ciclo seja apresentado para os demais grupos da classe.

Finalizada a intervenção da professora em cada um dos grupos, a mesma solicitou que as crianças em grupo, socializassem aos demais integrantes da sala, as produções discursivas específicas elaboradas.

\section{Discussão teórica}

Nas transcrições, notamos que a professora buscou produzir discursos referentes aos gastos com água virtual de um determinado produto. Com esse objetivo, 
diversos discursos foram elaborados: sobre ciclo de produção de um alimento, sobre a quantidade de água utilizada na produção de leite e da manteiga, bem como, sobre a constatação de que a informação sobre o consumo de água virtual, não está presente nas faturas do consumo de água ou ainda, nas embalagens dos produtos.

Assim, podemos destacar que a produção discursiva da professora dos anos iniciais não foi uma produção disciplinar, ou seja, não identificamos unicamente, a produção de discursos matemáticos escolares. Embora, seja essa uma questão proporcionada pela utilização da modelagem como ambiente de aprendizagem, haja vista ser definida, pela utilização de temas reais (BARBOSA, 2003; BURAK; KLUBER, 2011), a coexistência de múltiplos discursos disciplinares é uma característica peculiar à prática pedagógica desse nível de ensino.

Nesse nível de ensino, a individualização não se restringe à individualização de um discurso disciplinar, ou seja, do discurso matemático escolar. A individualização se opera em relação ao objetivo de se produzir discursos sobre água virtual, em particular, sobre a identificação do que vem a ser água virtual, como se identifica esses gastos e como evitá-los. Podemos identificar na atividade de modelagem analisada neste artigo que para nós, esse fato ocorreu em virtude de a professora adotar uma perspectiva sociocrítica de modelagem (BARBOSA, 2003; BARBOSA; SILVA, 2011; OREY; ROSA, 2007).

Muitos autores destacam que em atividades de modelagem, o papel do professor se redimensiona. O professor passa a ser o mediador do processo (BURAK; KLUBER, 2011; OLIVEIRA, CAMPOS; SILVA, 2009).

Nos discursos analisados nesse artigo, podemos destacar que a professora possuiu o discurso líder na produção discursiva das crianças, nos termos de Sfard (2008). O discurso líder assumido pela professora durante todo o desenvolvimento da atividade, teve para nós três papéis distintos. O primeiro, de ampliar a produção discursiva das crianças sobre o determinado tema água virtual. $\mathrm{O}$ segundo papel desempenhado pela professora na produção discursiva das crianças se referiu a dar legitimidade aos discursos produzidos por elas. As falas da professora, "é isso", "isso é interessante" são exemplos.

Outro papel desempenhado pela professora na produção de discursos pelas crianças foi o de avaliar e suscitar a coerência dos mesmos no que se referente à produção discursiva matemática correta pelas crianças. Os discursos matemáticos 
relativos aos procedimentos de adição, subtração e divisão etc. produzidos pelas crianças nos apontam para essa questão.

Embora possamos identificar a existência da adoção dos três acordos, tais quais, sugeridos por Sfard (2008), podemos observar que esses acordos se constituíram de maneira singular.

Isso porque talvez, possamos identificar que em atividades de modelagem, a possibilidade de interação discursiva entre professor e alunos, permite que a produção discursiva dos alunos também seja adotada como fonte para individualização de discursos e não apenas, a produção discursiva do professor.

Citamos como exemplo, a pergunta de uma criança sobre o que é metro cúbico à professora. Esse questionamento foi utilizado pela professora para a identificação pelas crianças de que a produção de soja consume muitos litros de água virtual. Também, em (17), podemos identificar que a criança sugere um tipo de discurso que quer produzir.

\section{Considerações finais}

A nosso ver, o professor mantém o papel de líder das produções discursivas dos alunos em tarefas de modelagem. No entanto, em atividades de modelagem é proporcionado às crianças que elas próprias sugiram produções discursivas que pretendem elaborar. Também, destacamos o fato de a professora desenvolver produções discursivas distintas em cada grupo de alunos, em uma mesma aula, sobre o tema água virtual.

Essa estratégia pedagógica adotada pela professora foi proporcionada pelo fato de que em atividades de modelagem, não se busca engessar uma maneira de desenvolvê-la e sua natureza é aberta. As sugestões de Barbosa (2003) referente aos Casos e as sugestões de Burak e Kluber (2011), em relação às etapas, são maneiras orientações para implementações de atividades de modelagem.

Nessa direção, podemos identificar que a opção da professora nesta pesquisa em suscitar nos alunos produções discursivas distintas, permitiu com que ela abordasse com os alunos produções discursivas diversificadas, adotando um papel de discursante líder não impositiva, mas que visou alinhar as produções discursivas das crianças sobre o gasto real de água na produção e consumo dos alimentos. 


\section{Referências}

ANGROSINO, M.V. Recontextualizing observation: ethnography, pedagogy, and the prospects for a progressive political agenda. In: DENZIN, N.K; LINCOLN. Y.S (Org.). The sage handbook of qualitative research. 3. ed. Thousand Oaks: Sage, 2005. p. 729-745.

BARBOSA, J. C. Modelagem Matemática e a Perspectiva Sócio-crítica. In: SEMINÁRIO INTERNACIONAL DE PESQUISAS EM EDUCAÇÃO MATEMÁTICA. 2, 2003, Santos. Anais... Santos: Sociedade Brasileira de Educação Matemática, 2003. 1 CD-ROM.

BARBOSA, J.C.; SILVA, J.N.D. Modelagem matemática e as discussões técnicas na interação entre professores e alunos. Boletim do GEPEM, v. 59, n. 2, p. 35-51, 2011.

BURAK, D.; KLÜBER, E.T. Modelagem Matemática na educação básica numa perspectiva de educação matemática. In: Educação Matemática: reflexões e ações. Curitiba: Editora CRV, p.147-166, 2011.

CALDEIRA, A.D. Etnomatemática e suas relações com a educação matemática na infância. In: BARBOSA, J. C.; CALDEIRA, A. D.; ARAÚJO, J. L. (Org.). Modelagem Matemática na Educação Matemática Brasileira: pesquisas e práticas educacionais. Recife: SBEM, 2007. p. 81-98.

CHARMAZ, K. Constructing grounded theory: a practical guide through qualitative analysis. Thousand Oaks: SAGE Publications, 2006.

DENZIN, N.K; LINCOLN. Y.S (Ed.). The sage handbook of qualitative research. 3. ed. Thousand Oaks: Sage, 2005. p. 675-728.

LAMON, S.J. Modelling. In: Elementar School: Helping Young Students to See the World mathematically. In.: LAMON. S.J; PARKER, WILLARD. A.P; HOSTON. KEN (Org). Mathematical Modelling: a way of life. ICTMA 11. Horwood Publising. Chichester, 2003, p. 19- 33.

LUNA, A.V.A.; SOUZA, E.G.;SANTIAGO, A.R.C.M. A Modelagem Matemática nas Séries Iniciais: o germén da criticidade. ALEXANDRIA Revista de Educação em Ciência e Tecnologia, 2, 135-157, 2009.

OLIVEIRA, A. M. P; CAMPOS, I. S.; SILVA, M. S. As estratégias do professor para desenvolver modelagem matemática em sala de aula. Boletim do GEPEM, v.55, n. 3, p. 175-192, 2009.

OREY, D. C; ROSA, M. A dimensão crítica da modelagem matemática: ensinando para a eficiência sociocrítica. Horizontes, v. 25, n. 2, p. 197-206, 2007.

SFARD. A. Thinking as communicating: human development, the growth of discourses, and mathematizing. Cambridge university press, 2008. 
SILVA, V.S; KLUBER, T.E. Um olhar pedagógico sobrea Modelagem Matemática nas séries iniciais do Ensino Fundamental. In: SEMINÁRIO DE PEDAGOGIA. 2. 2011, Irati. Anais... Irati: Departamento de Pedagogia da Universidade Estadual do CentroOeste, 2011.

SOUZA, E.G.; BARBOSA, J. C. Modelar matematicamente uma situação-problema: um enfoque participacionista.In.: CONFERÊNCIA NACIONAL DE MODELAGEM MATEMÁTICA, 6.,2009, Londrina. Anais... Paraná, 2009, 1 CD-ROM.

SKOVSMOSE. O. Educação Matemática Crítica : a questão da democracia.

Campinas: Papirus, 2001.

WENGER, E. Communities of practice: learning, meaning, and identity. New York: Cambridge University Press, 1998. 